\title{
INNOWIZ: DESIGN SPRINTING FOR SECONDARY SCHOOLS
}

\author{
Laura WILLEMS and Dries LAPERRE \\ Industrial Design Center, HOWEST Bach. Industrial Product Design (Belgium)
}

\begin{abstract}
INNOWIZ (innovation wizard) is an easy to learn creativity method that on one hand helps chaotic people to find structure and deliver on time, and on the other hand helps structured people to experiment more and spice up their ideas. The method and supportive tools are designed to allow a personal approach and use. Since 2009 INNOWIZ is integrated in different bachelor programmes (industrial product design, communication management, tourism, architecture, journalism, physiotherapy, ...) at HOWEST and other university colleges in Belgium, The Netherlands, Spain, USA, and China. Since 2014 Howest Industrial Design Center (IDC) delivers INNOWIZ-based services in research projects, innovation studies and processes in the making industry for universities, companies and organisations. In 2012 the Flemish Government decides to write a STEAM-chapter with 8 goals to achieve before 2020. It announced a new approach in education and launched different calls for innovation. HOWEST and especially IDC were asked to transfer their knowledge in design thinking and applied creativity, which lead to several new tools and support for secondary schools, their staff and pupils:

INNOWIZ TEMPLATE SET:

Based on the 4 steps INNOWIZ methodology - (1) problem definition, (2) idea generation, (3) idea selection, (4) idea communication - the INNOWIZ template set provides 12 templates in each step to help pupils to get started in their project with a creative approach. With a minimum of explication and a maximum of freedom, they learn how to find solutions by iteration. It helps them to get started as problem solvers and become familiar with open projects and wicked problems.

ONO STEAMKIT:

ONO is an abbreviation for 'Onderzoekend eN Ontwerpend leren' (Dutch), and can be translated as 'learning by research and design'. The ONO steamkit supports a group of teachers to think about project work that transcend the boundaries of courses and to discuss about teaching formats and the freedomto-operate for their pupils. Based on divergent and convergent thinking it allows teachers to get prepared for their role as coach and concurs the threshold to get started with project based learning.

After thoroughly testing in different types of schools, both tools have shown that the integration of applied creativity and the independence of high school pupils in the approach of the project effectively improve their motivation to bring the project to a successful solution. Not only the students, but also their teachers have experienced a positive effect while using the tools. Interdisciplinary teams can now, with help of the ONO-kit, organise their meetings in a clear and visually communicative way, so all teachers can agree upon the project, its boundaries and the participation of their pupils.

This paper will explain the tools, show how to use and reflect on the first effects on users and projects.
\end{abstract}

Keywords: Design methodology, creativity, education, open project approach, STEAM-education, design thinking, wicked challenges, co-design, project-based learning

\section{THE CONTEXT OF STEAM-EDUCATION IN FLANDERS}

In 2012, as one of the last European regions, the Flemish Government decided to write a STEAMframework with eight goals to achieve by 2020 . The framework announced a new approach in education and launched different calls for innovation. A lot of new initiatives in schools were raised and the backlog in primary and secondary schools would undergo fast recovery. In practice, this recovery took more time than planned: the challenge was more complex, the habits in education were stronger than expected. The interpretation of STEAM and the best approach to rethink education raised a lot of 
discussions. The lack of specific guidelines in the STEAM-framework led to an outgrowth of misinterpretations and contradictory solutions.

In 2018, two years before the final deadline, Flemish education is halfway through the challenge. In September 2019 - the start of a new academic year-, secondary schools will be asked (forced) to rethink classic organisation of different skills and knowledge in separate classes (mathematics, languages, science, ...), and start a mixed approach on teaching: history teachers will for instance have to collaborate with the French teachers (CLIL), geography will join mathematics,... Because of this, the modus of classic knowledge transfer will shift towards project-based learning, competence orientated evaluation, wicked challenges, teamwork and co-creation with (local) companies and organisations.

One of the most important lessons learned in the first attempts of secondary schools to apply design thinking in secondary education was that it is not something you can learn in a half day workshop. The only way for students (and teachers!) to build skills and confidence is to explore the possibilities themselves through exercise. Therefore, Howest Industrial Design Center (IDC) decided in 2016 to translate the experience in educating designers into low-threshold tools for educators and their students enabling them to explore these new challenges.

\section{THE CHALLENGES TEACHING STAFF AND PUPILS ARE FACING}

Trying to explore and understand the reason why first attempts of secondary schools didn't deliver the wanted result, interviews and observations with over more than 20 teachers revealed these first facts and insights:

- Teachers in secondary education do not longer design their own classes. They buy their lessons including (digital) books, manuals, slides, evaluation matrices, tasks, assignments and examination.

- A university college student in education is trained to use those educational products, and no longer to design his or her own lessons.

- Teachers in secondary education are confronted with a lot of boundaries concerning time, place, tools and budget, and have to check more than one box when pupils have to be evaluated.

- There is as good as no experience in collaboration between teachers of different disciplines.

- Teachers are obliged to participate in STEAM-courses or projects, whether or not they are motivated to do so.

- Students are forced in to project-based education, but do not have any tools or background nor support to tackle this new situation.

Next to the interviews and observations, a series of group discussions, expert brainstorms with a select group of 12 schools were organised. More questioning pupils, students, teachers, coordinators, educational managers and pedagogic experts led to a few specific needs, demands and wishes:

- Open tools (\& training) to use in class with students to train creativity and apply the acquired skills in project/team work.

- Open tools ( \& training) to be able to co-create during preparations of new projects with colleagues from other disciplines.

- Good examples and best practices.

- (self) Support and/or platform to share experience and find inspiration.

- $\quad$ Empowerment to get started.

\section{FOCUS AND STRATEGY}

Two of the abovementioned needs caught attention. First of all, the struggle pupils experience while executing a STEAM project. Secondly the big threshold for teachers to organise, communicate and plan a multidisciplinary project.

As an answer to these challenges, two tools were created. First of all, INNOWIZ, an easy to learn creativity method, and its redeveloped template set with as a focus group youngster from 14 to 18 years will support pupils to tackle the challenges in STEAM-projects. Secondly, ONO, a tool for teaching staff to help them spread out the project-based learning, will support teachers in their search for STEAMprojects and how to initiate them.

Because we believe, and it has been proved by our experience in development of former INNOWIZ tools and brainstorm sessions for numerous companies, that paper is the most efficient medium to stimulate and support communication in a co-creative atmosphere, we chose to start the development of 
paper-based tools. Once its use and effectiveness are proven by various tests, continuation of both tools to a digital focus can start (2019).

\section{TOOLS}

\subsection{Tool for short design sprint: INNOWIZ for education}

INNOWIZ (Innovation Wizard) is a creativity method that helps chaotic people to find structure and deliver on time and helps structured people to experiment more and spice up their ideas. The method and supportive tools are designed to allow a personal approach and use. Since 2009 INNOWIZ is integrated in different bachelor programmes (industrial product design, communication management, tourism, architecture, journalism, physiotherapy, ...) at HOWEST and other Universities of Applied Sciences in Belgium, The Netherlands, Spain, US, and China. Since 2014 Howest Industrial Design Center (IDC) delivers INNOWIZ-based services in research projects, innovation studies and processes in the making industry for companies and organisations. At the same time, we received a lot of requests from secondary schools to help them out with project work and creative problem solving.

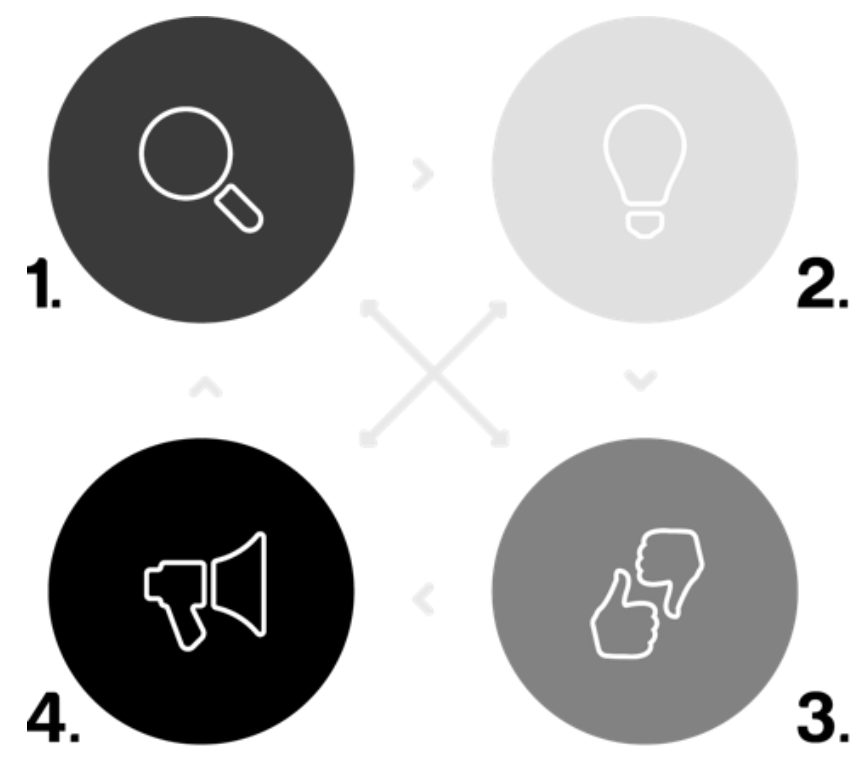

Figure 1. INNOWIZ steps

In 2016 INNOWIZ launched an English tool based on 50 organised templates (figure 2.), that support creativity each in a different phase of the creativity process. Based on the 4 steps in the INNOWIZ methodology (figure 1.) - (1) problem definition, (2) idea generation, (3) idea selection, (4) idea communication - the INNOWIZ template set provides 12 templates in each step to support pupils to get started with a creative approach in their project. With a minimum of explication and a maximum of freedom, young adults learn how to find solutions in an iterative approach. It helps them to get started as problem solvers and become familiar with open projects and wicked problems. It structures and labels all the actions that trained designers spontaneously do when being creative. 


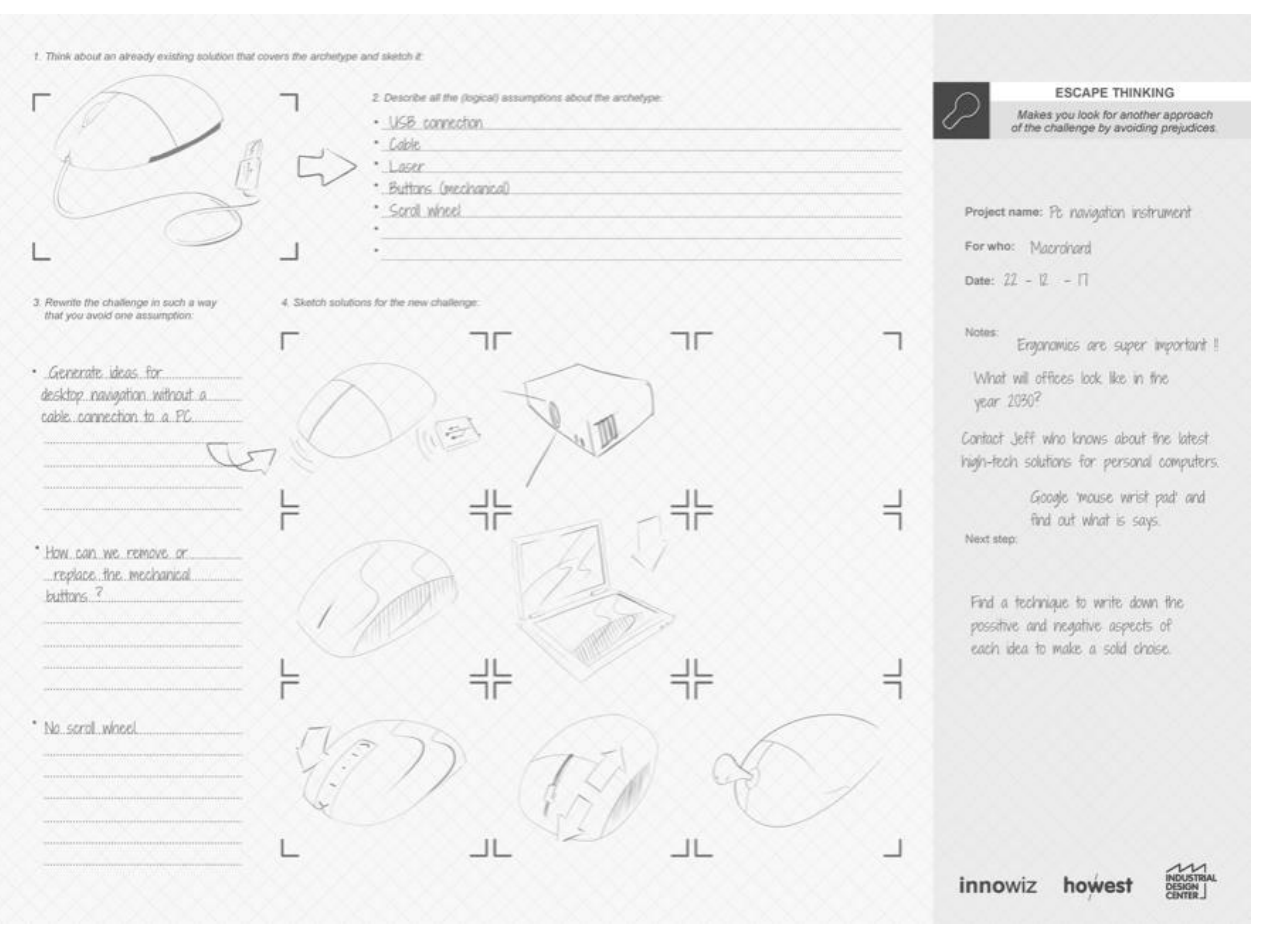

Figure 2. Example of INNOWIZ template

This tool formed the backbone for a similar tool, adapted to its new users: secondary teachers and their students. While adapting the tool to the new user group, some practical issues had to be solved:

- $\quad$ Adjust the used language in the templates from English to native language (Dutch)

- Change the usage of the language from formal to simple

- $\quad$ Add a more playful look 'n' feel

- Less suggesting that they are making a filling exercise, suggesting there is only one right answer.

- Inviting them to use it in their own way as they prefer far beyond the manual they are used to

After a few prototypes and tests in classes (figure 3.and 4) later, we were able to present the new youngster-friendly version of the INNOWIZ template set in Dutch. The tool makes it possible for students to use it on their own, after an introduction of the teacher. Of course, this tool also works for teachers to use during preparation, when rethinking their own classes, lessons, assignments, etc....

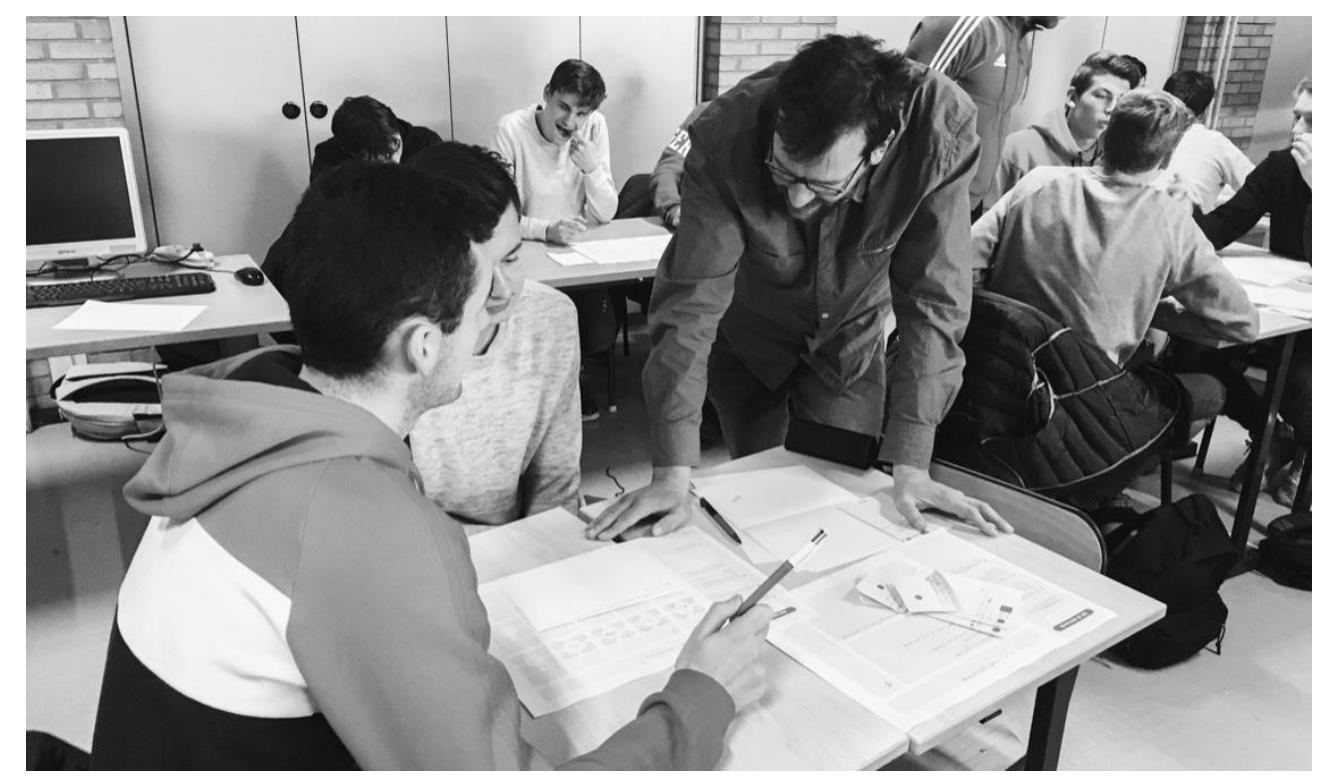

Figure 3. Testing the new INNOWIZ templates with high school students 


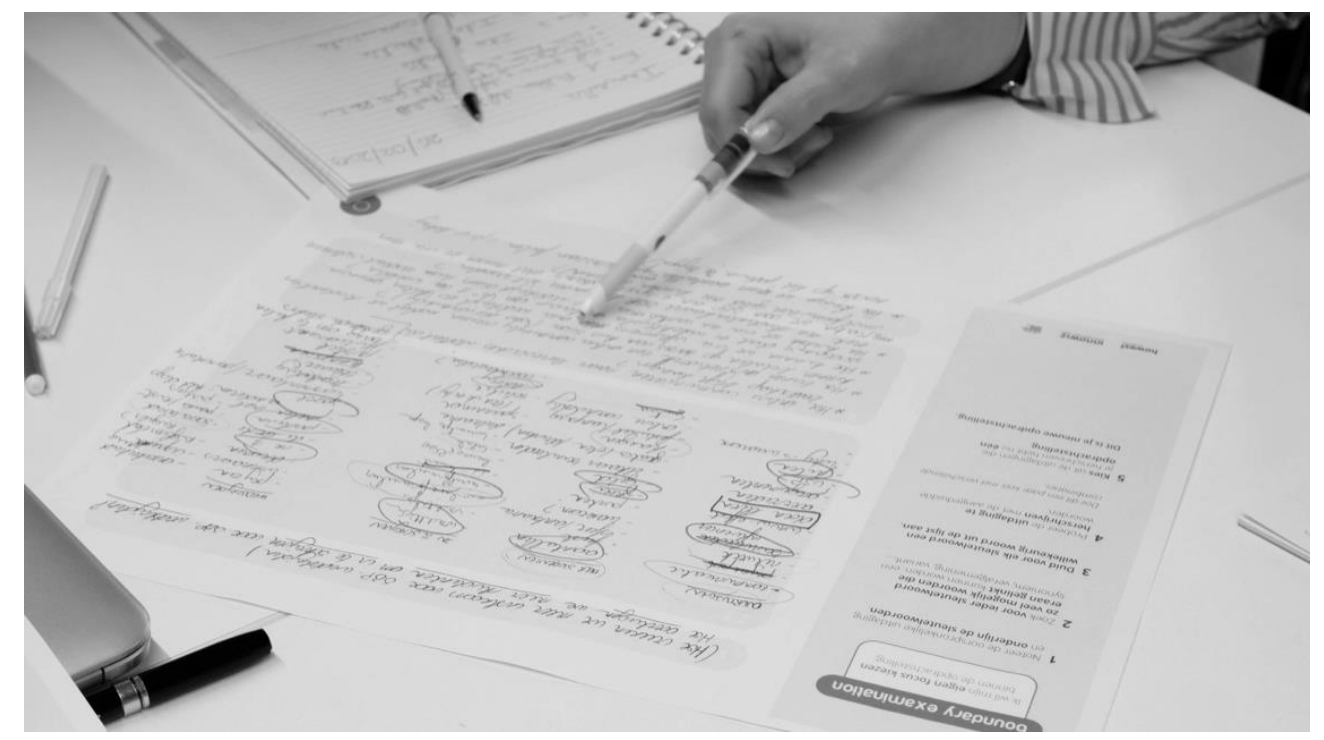

Figure 4. Testing the new INNOWIZ templates with high school students

In addition to the English version of INNOWIZ a vast manual about the INNOWIZ backdrop was added to the tool: how to get started with an INNOWIZ design sprint, some example pathways of successful design sprints and - most appreciated by teachers of all - a guideline to choose a convenient technique for a specific challenge. A selection matrix - with for each step different criteria - narrows the choice from 12 to two or three possible suitable techniques applicable for the topic of the design sprint.

The demand for the new INNOWIZ tool is increasing and teaching staff are actively on the look for support and tools. For this reason, the tool will be distributed from June awards on and the organisation of a train-the-trainer session for secondary school teachers will follow shortly after that.

\subsection{Tool for planning and preparing project work: ONO}

In 2017 the HOWEST department of Industrial Product Design was granted a budget to carry out an applied research project concerning the challenges secondary education is facing by engaging in projectbased learning. Next to our already 20 years of experience in project-based education and design thinking, it was clear that there had to be teamed up with the teacher training institute of HOWEST. Together with them and in co-creation with secondary school teachers, a didactically underpinned and open approach tool for educators of secondary schools, called ONO, was developed.

ONO is the abbreviation for 'Onderzoek eN Ontwerp' (Dutch) and can be translated as 'learning through research and design'. The goal of ONO is to support a group of teachers to think about project work that transcends the boundaries of courses and to let them discuss about teaching formats and the freedomto-operate of their students.

The tool itself exists out of 3 different elements:

- A board with two different axes: one concerning the timeframe of the project, the other opens discussion about the autonomy of the pupils

- Cards which represent milestones in a research and design process: e.g. Research question, proof of concept.

- Cards that describe actions students have to undertake to accomplish the milestones that are set: e.g. gather information, reflection on outcome, develop ideas. 


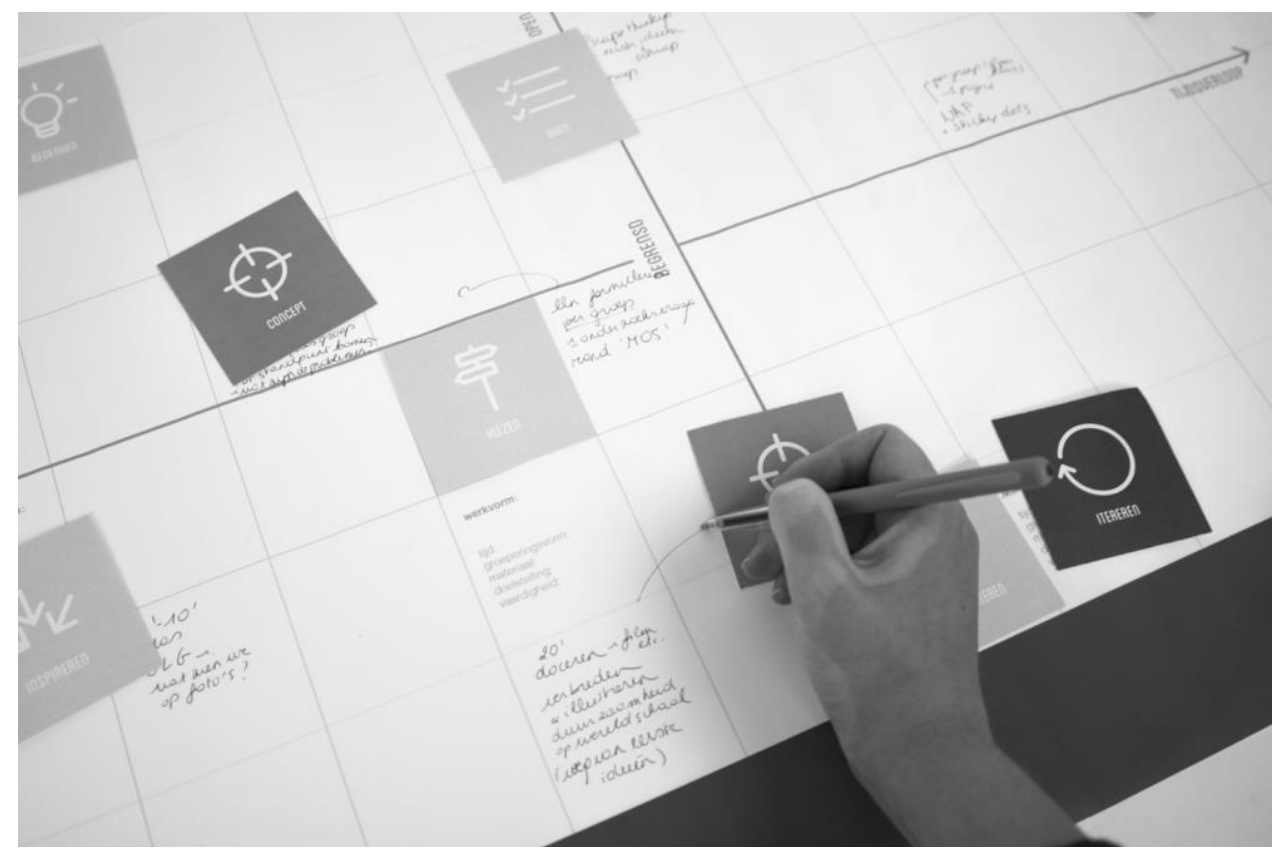

Figure 5. ONO in use

When teachers are getting started with a new project in ONO, there are a few steps to follow:

- $\quad$ Agree upon the goal and different in-between milestones they want to handle in the project

- $\quad$ Think of different actions pupils have to go through to achieve the milestones

- Once all cards are in chronological order at the bottom of the board, the teachers can discuss about the autonomy of the pupils for each action/milestone. There are 3 zones on the vertical axis the cards can be placed in: closed, between boundaries and open.

After fixating the vertical position of the cards, some practicalities have to be defined such as: time, evaluation, which teacher will take care of the action or milestone, which objectives are attained, which creativity technique (link INNOWIZ) they should or could use, ...

After going through these steps, the board is completed, and the project preparations are documented and ready to use in class to introduce the process.

ONO enables multidisciplinary teacher teams to communicate in an efficient and effective way. Teachers are forced to think beyond the standard ways of instructing a course and are pointed out at the possibility to transfer more responsibility to the students on their own project.

ONO can not only be used by teachers alone but can also serve as a communication tool for the students to explain the project and process they will go through. When ONO is used from first/second grade on, last year students will be able to use ONO themselves and thus ownership will increase.

\section{OVERALL CONCLUSIONS}

After testing both tools elaborately and gathering feedback, enthusiasm is present among the teachers, pupils and University College students in education. The overall conclusions are that the tools:

- Are easy to use; easy to explain, easy to apply and integrate in project work

- Help to communicate in groups and translate the discussions or brainstorms into practical decisions, results and to-dos.

- $\quad$ Trigger young pupils to be more creative and decide for their own (ownership)

- Help motivated (pioneer) teachers to convince other colleagues to participate in an open project

The direction and the management appreciate the hands-on application and the fact it has a low threshold to get started. The tools are open for customisation which lets different stakeholders use the tools as they prefer to use it: the type of challenge, the composition of the team or the topic related to the challenge have no (negative) impact on how to use the tools. There is no wrong or right way to use: if you use it as you think you should use it, it will work.

Users are curious to the digital possibilities of both the tools and want to know how they can learn more by sharing cases and experiences. This opens also opportunities for the research team, to learn in which different ways the tools are used, which techniques are common and successful, which new needs float up. 